\title{
Efficacy and Tolerability of Valganciclovir 6 Months vs 6 Weeks in Symptomatic Cytomegalovirus Infection in Infants: An Open Level Randomized Controlled Trial
}

\author{
N. A. Ruby, M. M. Rahman, S. Akhter, N. Sultana
}

\section{ABSTRACT}

Congenital cytomegalovirus (CMV) infection is the most common transplacental infection affecting neurodevelopment in infant, commonly hearing and cognitive impairment. This study aimed to compare 6 weeks with 6 months duration of oral valganciclovir in respect of efficacy and tolerability. This randomized controlled trial was conducted in both outpatient and inpatient pediatrics department of a tertiary hospital, on123 infants aged 0-12 months with polymerase chain reaction proven congenital CMV infection over a period of 18 months. The children were divided into two groups, according to the treatment group they belonged to, one is 6 weeks group and other is 6 months group. The children were followed up for 12 months at 3-month interval to compare the virological clearance, psychological, visual, and hearing status, and side effects of drug. The viral load assessment was done at 6 weeks, 6 months, and 12 months of the initial treatment. Mean age of the infants of 6 weeks group is $7.33 \pm 1.74$ months and that of 6 months group is $6.70 \pm 2.23$ months. Primary outcome is the clearance of virus, exhibited in both groups significantly at 12 weeks of follow up but $100 \%$ clearance of virus observed in 6 months group at 6 months of follow up. Whereas 5 patients at 12 weeks and 3 patients at 6 months have shown non clearance of virus among the 6 weeks treatment group. Total $50(80.6 \%)$ patients hearing return to normal at 12 months follow up in 6 months treatment group compared to $31(50.8 \%)$ in 6 weeks group $(p=0.001)$. Visual improvement also observed among 58(93.5\%) patients of 6 months group and $48(78.7 \%)$ in 6 weeks group and this difference is statistically significant $(p=0.01)$. At 12 months of follow up 6 months group had shown better neurodevelopmental outcome $(p=0.00)$. Both groups exhibit good tolerance to drug.

Conclusion: 6 months duration treatment of valganciclovir in symptomatic CMV infection have shown better neurodevelopmental outcome and visual, auditory improvement compared to 6 weeks duration.

Keywords: Cytomegalovirus, neurodevelopment, valganciclovir.
Published Online: January 11, 2022

ISSN: $2736-5476$

DOI: 10.24018 /ejclinicmed.2022.3.1.122

N. A. Ruby*

Dhaka Medical College, Bangladesh.

(e-mail: nazninruby73@gmail.com)

M. M. Rahman

Bangabandhu Sheikh Mujib Medical

University, Bangladesh.

(e-mail:

mizanur rahman 1995@yahoo.com)

S. Akhter

Bangabandhu Sheikh Mujib Medical University, Bangladesh.

(e-mail: shaheen@ cnacbangladesh.org)

N. Sultana

Sher-e-Bangla Medical College, Bangladesh.

(e-mail: nasrinsultana@gmail.com)

*Corresponding Author

\section{INTRODUCTION}

Congenital cytomegalovirus (CMV) infection is the most common congenital infection of human affecting $0.6 \%-0.7 \%$ of live births in developed countries to $1 \%-5 \%$ in resource poor countries [1], [2]. The seroprevalence of infection varies between $65 \%$ and $90 \%$ among middle-aged adults in USA, where primary CMV infection during pregnancy occurs in $2 \%$ of women of childbearing age ranged from middle to higher socioeconomic groups and $6 \%$ of women from lower socioeconomic background [3]-[5]. overcrowding, poor sanitation, poor hygiene and unsterile delivery practice may contribute to transmit the virus to fetus, infants, and children. Newborn can acquire CMV infection through transplacental route during intrauterine period, during process of birth and from the breast milk. Maternal infection immediately prior to pregnancy and during pregnancy increase the risk of congenital CMV infection [6], [7]. Transmission of infection at early gestational age is usually associated with poor neurodevelopmental outcome [8]-[10] The level of maternal virus load directly correlates to the risk of perinatal and postnatal infection. Excretion of virus through breast milk is greatest between 2 weeks to 2 months of postnatal age, where the risk of infection varies from $39 \%$ to $59 \%$ [11], [12].

Congenital CMV infection is defined as active infection detectable within the first 3 weeks after birth which is diagnosed by detection of CMV DNA in the urine, saliva, or blood with evidence of central nervous system involvement, including SNHL, psychomotor delay, chorioretinitis, any stigmata of CMV infection, any preterm presented with life 
threatening critical illness like pneumonitis, hepatitis or encephalitis [13], [14].

Around $90 \%$ of the infection remains asymptomatic or self-limited in healthy children and adults, leaving the rest to exhibit clinical symptoms of congenital CMV. In immunocompromised hosts and infected fetuses, though, CMV produces a high burden of diseases [15], [16]. Usual symptoms and signs of congenital CMV infections include jaundice, petechiae and hepatosplenomegaly constituting the classical triad on congenital CMV infection. Central nervous system (CNS) involvement is present in about two third of all cases of infants [14], which includes microcephaly, seizure, motor developmental delay, cognitive and speech delay, learning disability and various forms of eye manifestations like optic atrophy, strabismus, chorioretinitis [3], [17], [18]. Different forms of congenital malformations of brain occur if the pregnant mother become infected in the early gestation which may manifested with refractory seizures and global developmental delay along with severe microcephaly, and in the developed world it is the leading non genetic cause of sensorineural hearing loss (SNHL) in children [19], [20]. Hearing loss is the most significant developmental abnormality in children with asymptomatic infection. One study found hearing loss in $7.2 \%$ of patients with asyptomatic infection [21].

Ganciclovir (GCV) and valganciclovir (VGCV) are the two important drugs that have been used to treat congenital CMV infection. GCV is a synthetic analogue of 2deoxyguanosine which is phosphorylated to ganciclovir monophosphate by a viral kinase encoded by the CMV gene UL97 during infection [12], [22]. VGCV is the oral prodrug of GCV. The National Institute of Allergy and Infectious Diseases Collaborative Antiviral Study Group (CASG) had conducted a randomized controlled trial on 100 neonates with symptomatic CMV with CNS involvement and found auditory improvement at 6 months as primary end point and improvement in growth and development as secondary end point but intravenous use of GCV required prolong hospital stay and as a primary toxicity of GCV around $63 \%$ of patients developed moderate to severe neutropenia [12]. Whereas VGCV is the oral prodrug of GCV having 10 times greater bioavailability compared to oral GCV. Kimberlin and colleagues had performed a comparative study of 6 weeks therapy of oral VGCV and intravenous GCV and found $6 \mathrm{mg} / \mathrm{kg}$ intravenous GCV and $16 \mathrm{mg} / \mathrm{kg}$ oral VGCV provide similar systemic efficacy [23]. In another randomized controlled trial Kimberlin et al have found 6 months oral VGCV provide better audiologic and neurodevelopmental outcome compared to 6 weeks VGCV with less toxicity [23], [24].

Though the burden of congenital CMV infection is high in developing country but has very limited study in this field. Prolong duration of oral VGCV provide sustainable audiologic and neurodevelopmental improvement need to be demonstrated. We propose this study to assess the neurodevelopmental improvement with oral VGCV at two different duration of treatment regime, namely 6 weeks and 6 months treatment groups.

\section{Methodology}

This open level randomized controlled trial was carried out in the outpatient and inpatient department of pediatrics in a tertiary care center. All the suspected infants (0-12 months) of congenital CMV infection with neurodevelopmental deficit was serologically confirmed by presence of CMV DNA in body fluid specially from urine, Real-Time PCR quantitative assay was performed to detect CMV DNA from urine, presence of more than 500 copies considered as positive. Total 150 patients were included in this study, 75 in each group but finally we assessed 123 patients 61 patients in 6 weeks group and 62 in 6 month's group, others were excluded due to non-compliance to treatment. Primary end point was clearance of virus and secondary end point was neurodevelopmental, visual and audiological improvement. Detail history regarding presenting complaints; neurodevelopmental problem like seizure, motor, cognitive, speech delay, pregnancy and birth related history, antenatal history, family and socioeconomic information, relevant past history was taken from attendance. Thorough regional examination including general and systemic examination was done. Informed written consent was taken from the caregiver. Randomization was done by lottery method, 6weeks group was considered as control and 6 months group was entitled as case. After enrollment all confirmed cases of congenital CMV infection underwent neuroimage (C-T scan of brain/ MRI of brain) and electroencephalography (EEG), other investigations were performed as per clinical indication.

Initial visual, hearing, and psychological assessment was done to all children. For auditory assessment Brainstem Auditory-Evoked Responses/ Auditory Brainstem Response (BAER/ABR) or Otoacoustic Emissions (OAEs) test was performed, and hearing was leveled as normal, mild, moderate, severe and profound impairment. Hearing thresholds were defined as follows: 0-20 DB for normal hearing, 21-45 DB for mild hearing loss, 46-70DB for moderate hearing loss and $71 \mathrm{DB}$ or higher for severe hearing loss, no response at all were graded as profound hearing loss [25]. Psychological assessment was done by using BSID-III (Bailey Scale of Infant Development-III), motor, language and cognitive assessment composite score was analyzed. Composite score $<55$ graded as severe impairment, 55-69 moderate and 70 to 84 as mild impairment, score 85 and above was considered as normal.

VGCV was given orally at a dose of $16 \mathrm{mg} / \mathrm{kg} / \mathrm{dose}$ for 12 hourly for 6 weeks duration in control group and for 6 months in cases, presence of chorioretinitis in visual assessment went to the 6 months duration protocol without randomization. At the end of 6 weeks treatment serologically positive control were not compared with cases finally. All the patients were followed up at 3 months interval regarding their neurodevelopmental, hearing, and visual improvement or deterioration. Urinary CMV DNA PCR was performed at 6 weeks, 12 weeks, and 6 months period to assess virus clearance. To assess the side effects of drugs baseline and weekly CBC, SGPT, S.Creatinine level was done. 


\section{Data Collection Procedure}

Data were processed and analyzed by using computer software SPSS (Statistical Package for Social Science) version21. Data presented on categorical scale are expressed as frequency and corresponding percentage, while the quantitative data are presented as mean and standard deviation $( \pm \mathrm{SD})$. Qualitative variables were assessed with chi-square test and the quantitative variables were analyzed with Student's t-test or one way ANOVA as applicable. We constructed the error bars of viral loads of both groups from initial (before treatment), and at 6 weeks, at 12 weeks and at 12 months after the treatment in excel. A $p$ value of $\leq 0.05$ was considered significant.

\section{RESUlts}

\section{A. Study Population}

From July 2018 to December 2019, total 150 patients were randomly assigned to this study, after receiving 6 weeks Valganciclovir 75 patients were continuing to receive the drug for total 6 months (6 months group-case) and 75 were assigned to receive placebo. Out of total 150 participants 27 (14 from 6 weeks group, 13 from 6 months group) failed to continue the treatment and follow up. No patients discontinued treatment due to adverse effects of drugs. Demographic characteristics are shown in Table I. Table I show that there is no significant difference in age between two groups. Most of the patients came from rural, poor socioeconomic and low education background with male predominance.

TABLE I: DEMOGRAPHIC CHARACTERISTICS OF THE STUDIED POPULATION [MEAN \pm SD/ N (\%) AS APPLICABLE]

\begin{tabular}{cccc}
\hline \hline Variables & 6 weeks & 6 months & P value \\
\hline \hline Age in month & & & \\
Sex of patients & $7.33 \pm 1.74$ & $6.70 \pm 233$ & 0.86 \\
Male & $41(67.2)$ & $44(71.0)$ & 0.65 \\
Female & $20(32.8)$ & $18(29.0)$ & \\
Residence & & & \\
Rural & $39(63.9)$ & $44(71.0)$ & \\
Urban & $07(11.5)$ & $06(9.7)$ & 0.70 \\
Urban slum & $15(24.6)$ & $12(19.4)$ & \\
Education $\mathrm{M}^{*}$ & & & \\
No & $15(24.6)$ & $24(38)$ & \\
Primary & $37(60.7)$ & $30(48)$ & 0.24 \\
Secondary & $09(14.8)$ & $08(12.9)$ & \\
Income** & & & \\
$<10,000$ & $25(41.0)$ & $21(33.9)$ & \\
$10,000-20,000$ & $33(54.1)$ & $37(59.7)$ & 0.70 \\
$20,000-40,000$ & $3(4.90)$ & $04(6.0)$ & \\
\hline \hline & & & \\
\hline mother, ** taka/month &
\end{tabular}

* mother, ** taka/month

\section{B. Perinatal Events}

The antenatal care, mode and site of delivery, gestational age, perinatal asphyxia and neonatal events were more or less homogeneously distributed in both groups of patients as evidenced in Table II.

\section{Clinical Manifestations}

Microcephaly, epilepsy, visual and hearing impairment along with cognitive, language and motor delay demonstrated as the major presenting features of both groups, movement disorder present in the form of dystonia more frequently. No significant difference in viral load in both groups but a little bit higher among 6 weeks group (Table III).

TABLE II: DISTRIBUTION OF STUDIED POPULATION ACCORDING TO PERINATAL EVENTS [MEAN \pm SD/ $\mathrm{N}(\%)$ AS APPLICABLE

\begin{tabular}{clll}
\hline \hline Perinatal Events & 6 weeks & 6 months & P value \\
\hline \hline ANC & & & \\
No & $9(14.8)$ & $14(22.6)$ & \\
Single & $30(49.2)$ & $29(46.8)$ & 0.17 \\
Two & $22(36.1)$ & $16(25.8)$ & \\
> Two & $00(0.0)$ & $3(4.8)$ & \\
Delivery site & & & \\
Home & $41(67.2)$ & $37(59.7)$ & 0.34 \\
Hospital & $20(32.8)$ & $25(40.3)$ & \\
Delivery model & & & \\
NVD & $33(54.1)$ & $37(59.7)$ & \\
Assisted & $19(31.1)$ & $11(17.7)$ & 0.18 \\
LUCS & $9(14.8)$ & $14(22.6)$ & \\
PNA & $16(26.2)$ & & \\
No & $45(73.8)$ & $20(32.3)$ & 0.46 \\
Yes & $8(13.1)$ & $92(67.7)$ & \\
Preterm & $37(60.7)$ & $39(62.9)$ & \\
Term & $15(24.6)$ & $12(19.4)$ & 0.86 \\
IUGR & $1(1.6)$ & $2(3.2)$ & \\
Post term & & & \\
& & & \\
\hline
\end{tabular}

TABLE III: DISTRIBUTION OF TWO GROUPS ACCORDINGTOCLINICALMANIFESTATIONS[MEAN \pm SD/ N (\%) AS

\begin{tabular}{|c|c|c|c|}
\hline Clinical Manifestations & 6 weeks & 6 months & P value \\
\hline \multicolumn{4}{|l|}{ Microcephaly } \\
\hline No & $17(27.9)$ & $21(33.9)$ & \multirow{2}{*}{0.47} \\
\hline Yes & $44(72.1)$ & $41(66.1)$ & \\
\hline \multicolumn{4}{|l|}{ Epilepsy } \\
\hline Focal & $13(35.1)$ & $15(34.1)$ & \multirow{6}{*}{0.01} \\
\hline Focal with Bilateral & $9(24.3)$ & $00(0.0)$ & \\
\hline GTCS & $5(13.5)$ & $10(22.7)$ & \\
\hline Infantile Spasm & $8(21.6)$ & $12(27.3)$ & \\
\hline Myoclonic seizure & $2(5.4)$ & $5(11.4)$ & \\
\hline Mixed & $00(0.0)$ & $2(4.5)$ & \\
\hline \multicolumn{4}{|l|}{ Movement disorder } \\
\hline Dystonia & $13(68.4)$ & $16(69.6)$ & \multirow{4}{*}{0.37} \\
\hline Tremor & $3(15.8)$ & $4(17.4)$ & \\
\hline Choreoathetosis & $1(5.3)$ & $3(13.0)$ & \\
\hline Stereotypy & $2(10.5)$ & $00(0.0)$ & \\
\hline \multicolumn{4}{|l|}{ Visual Impairment } \\
\hline Normal & $21(34.4)$ & $27(43.5)$ & \multirow{5}{*}{0.003} \\
\hline Central visual impairment & $35(57.4)$ & $26(41.9)$ & \\
\hline Chorioretinitis & $00(0.0)$ & $9(14.5)$ & \\
\hline Papilledema & $2(3.3)$ & $00(0.0)$ & \\
\hline Nystagmus & $3(4.9)$ & $00(0.0)$ & \\
\hline \multicolumn{4}{|l|}{ Hearing Impairment } \\
\hline Normal & $8(13.1)$ & $18(29.0)$ & \multirow{4}{*}{0.14} \\
\hline Mild impairment & $29(47.5)$ & $20(32.3)$ & \\
\hline Moderate impairment & $23(37.7)$ & $23(37.1)$ & \\
\hline Severe impairment & $1(1.6)$ & $01(1.6)$ & \\
\hline \multicolumn{4}{|l|}{ Motor delay } \\
\hline Mild & $00(0.0)$ & $2(3.2)$ & \multirow{3}{*}{0.32} \\
\hline Moderate & $8(13.1)$ & $10(16.1)$ & \\
\hline Severe & $53(86.9)$ & $50(80.6)$ & \\
\hline \multicolumn{4}{|l|}{ Language delay } \\
\hline Mild & $00(0.0)$ & $3(4.8)$ & \multirow{3}{*}{0.04} \\
\hline Moderate & $3(4.9)$ & $9(14.5)$ & \\
\hline Severe & $58(95.1)$ & $50(80.6)$ & \\
\hline \multicolumn{4}{|l|}{ Cognitive delay } \\
\hline Mild & $00(0.0)$ & $3(4.8)$ & \multirow{3}{*}{0.07} \\
\hline Moderate & $4(6.6)$ & $9(14.5)$ & \\
\hline Severe & $57(93.4)$ & $50(80.6)$ & \\
\hline Initial Viral load & $\begin{array}{c}304132.1967 \\
\pm 672879.2\end{array}$ & $\begin{array}{c}252617.4194 \\
\pm 431710.9\end{array}$ & 0.61 \\
\hline
\end{tabular}

\section{EEG Findings of both Groups}

Majority of patients from both groups have no EEG changes, most common changes are focal and burstsuppression pattern. Hsyparrythmia, burst-suppression and 
multifocal pattern of EEG changes observed among the patients with infantile spasm (Table IV).

TABLE IV: DISTRIBUTION OF TWO GROUPS ACCORDING TO EEG

\begin{tabular}{cccc}
\multicolumn{4}{c}{ FINDINGS $($ MEAN \pm SD / N (\%) AS APPLICABLE) } \\
\hline \hline Initial EEG & 6 weeks (n=61) & 6 months (n=62) & \multirow{2}{*}{ P value } \\
Findings & Frequency (\%) & Frequency (\%) & \\
\hline \hline No abnormalities & $34(55.7)$ & $30(48.4)$ & \\
Focal discharge & $10(16.4)$ & $8(12.9)$ & \\
Generalized & $5(8.2)$ & $6(9.7)$ & \\
Discharge & $4(6.6)$ & $2(3.2)$ & \\
Multifocal & $3(4.9)$ & $5(8.1)$ & 0.21 \\
Hsyparrythmia & $3(4.9)$ & $11(17.7)$ & \\
Burst - Suppression & $2(3.3)$ & $00(0.0)$ & \\
Slow wave & &
\end{tabular}

\section{E. Neuroimage Findings}

Table V shows cortical atrophy, diffuse encephalomalacic change, intracranial calcification, congenital malformations of brain are the most common neuroimage findings observed between two groups and there is no significant difference in neuroimage findings on two groups.

TABLE V: NEUROIMAGE FINDINGS OF STUDIED POPULATIONS*[MEAN \pm SD/ N (\%) AS APPLICABLE]

\begin{tabular}{cccc}
\hline \hline Neuroimage findings & 6 weeks & 6 months & P value \\
\hline \hline Normal & $4(6.6)$ & $3(4.8)$ & 0.68 \\
Cortical atrophy & $56(91.8)$ & $50(80.6)$ & 0.07 \\
DEC & $17(27.9)$ & $20(32.3)$ & 0.60 \\
CMB & & & \\
Schizencephaly & $00(0.0)$ & $1(1.6)$ & \\
Lissencephaly & $3(4.9)$ & $4(6.5)$ & 0.07 \\
CCA\&Colpocephaly & $6(9.8)$ & $7(11.3)$ & \\
Hemimegalencephaly & $1(1.6)$ & $2(3.2)$ & \\
ICC & $32(52.5)$ & $36(58.1)$ & 0.53 \\
BGH & $19(31.1)$ & $24(38.7)$ & 0.38 \\
\hline \hline
\end{tabular}

\section{F. Clearance of Virus}

The Fig. 1 shows that though the 6 weeks group of children had slightly higher initial viral load compared to 6 months group, they quickly came down almost to zero at 6 weeks and maintained as such throughout the course of 12 weeks and 6 months. The 6 months treatment group, though had a lower viral load compared to 6 weeks group, they also came down near to zero after 6 weeks of treatment and thus maintained throughout the course of 12 weeks and 6 months. But they still had few infections at the end of 6 months among the 6 weeks group. The difference between these two viral load remissions and the individual group remission has become statistically significant $(\mathrm{p}<0.001)$, which is mainly attributed by the reduction from initial load to the load at 6 weeks.

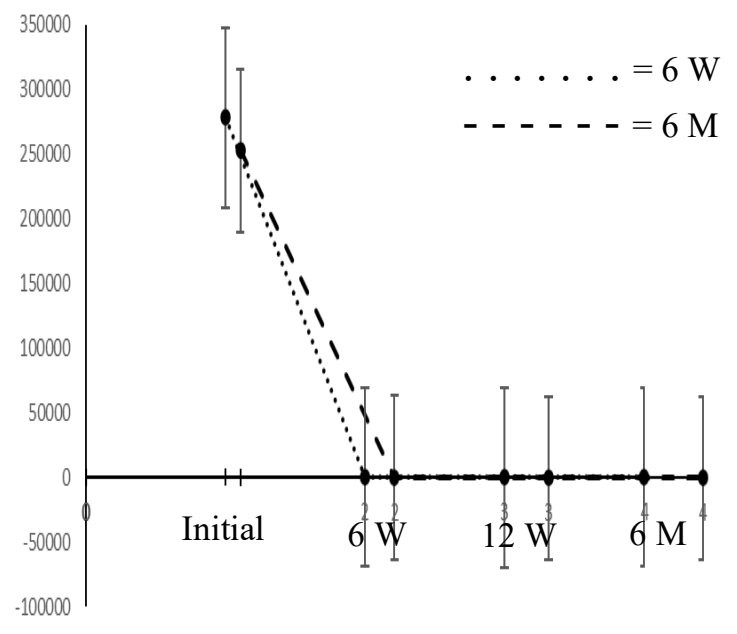

Fig. 1. Virus load of both groups at different time interval.

\section{G. Hearing Outcome}

At the 6 months after initial assessment, it has shown significant improvement of hearing status among the 6 months group. At the 12 months of follow up this improvement continued shown in (Fig. 2).

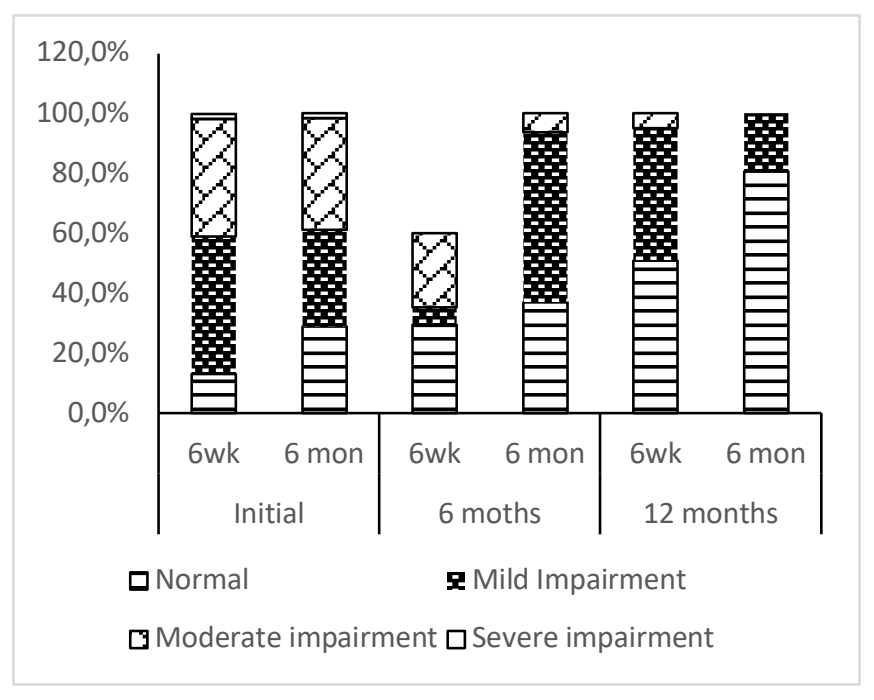

Fig. 2. Hearing outcome of studied population.

\section{H. Visual Outcome}

As all the cases of chorioretinitis included in 6 months group treatment so initial status has shown significant statistical difference, at the 6 months period we have found significant improvement of CVI among the 6 months group which also maintained at 12 months of follow up compared to 6 weeks group shown in (Table VI).

\begin{tabular}{|c|c|c|c|c|c|c|}
\hline $\mathrm{Gr}$ & Normal & CVI & $\mathrm{CR}$ & Pap & Nys & $\mathrm{p}$ \\
\hline \multicolumn{7}{|c|}{ Initial $\mathrm{F} / \mathrm{U}$} \\
\hline $\begin{array}{l}6 \text { weeks } \\
6 \text { months }\end{array}$ & $\begin{array}{l}21(34.4) \\
27(43.5)\end{array}$ & $\begin{array}{l}35(57.4) \\
26(41.9)\end{array}$ & $\begin{array}{l}00(0.0) \\
9(14.5)\end{array}$ & $\begin{array}{c}2(3.3) \\
00(0.0)\end{array}$ & $\begin{array}{c}3(4.9) \\
00(0.0)\end{array}$ & 0.003 \\
\hline \multicolumn{7}{|c|}{6 months $\mathrm{F} / \mathrm{U}$} \\
\hline $\begin{array}{c}6 \text { weeks } \\
6 \text { months } \\
\end{array}$ & $\begin{array}{l}35(57.4) \\
45(72.6) \\
\end{array}$ & $\begin{array}{l}26(42.6) \\
13(21.0) \\
\end{array}$ & $\begin{array}{c}00(0.0) \\
4(6.5) \\
\end{array}$ & $\begin{array}{l}00(0.0) \\
00(0.0) \\
\end{array}$ & $\begin{array}{l}00(0.0) \\
00(0.0) \\
\end{array}$ & 0.025 \\
\hline \multicolumn{7}{|c|}{12 months $\mathrm{F} / \mathrm{U}$} \\
\hline $\begin{array}{l}6 \text { weeks } \\
6 \text { months }\end{array}$ & $\begin{array}{l}48(78.7) \\
58(93.5)\end{array}$ & $\begin{array}{c}13(21.3) \\
3(4.8)\end{array}$ & $\begin{array}{c}00(0.0) \\
01(1.6)\end{array}$ & $\begin{array}{l}00(0.0) \\
00(0.0)\end{array}$ & $\begin{array}{l}00(0.0) \\
00(0.0)\end{array}$ & 0.01 \\
\hline
\end{tabular}




\begin{tabular}{|c|c|c|c|c|c|c|}
\hline F/U & Cog score & P value & Mot score & P value & L score & P value \\
\hline \multicolumn{7}{|c|}{3 months } \\
\hline $\begin{array}{l}6 \text { weeks } \\
6 \text { months }\end{array}$ & $\begin{array}{c}43.7 \pm 8.5 \\
44.6 \pm 14.2\end{array}$ & 0.01 & $\begin{array}{c}46.6 \pm 8.8 \\
54.5 \pm 10.3\end{array}$ & 0.14 & $\begin{array}{c}44.1 \pm 7.8 \\
50.7 \pm 12.3\end{array}$ & 0.02 \\
\hline \multicolumn{7}{|c|}{6 months } \\
\hline $\begin{array}{l}6 \text { weeks } \\
6 \text { months }\end{array}$ & $\begin{array}{c}48.6 \pm 8.5 \\
51.7 \pm 14.1 \\
\end{array}$ & 0.01 & $\begin{array}{c}52.4 \pm 8.8 \\
66.6 \pm 11 \\
\end{array}$ & 0.0 & $\begin{array}{l}49.5 \pm 7.8 \\
59 . \pm 12.2 \\
\end{array}$ & 0.00 \\
\hline \multicolumn{7}{|c|}{9 months } \\
\hline $\begin{array}{l}6 \text { weeks } \\
6 \text { months }\end{array}$ & $\begin{array}{c}54.4 \pm 8.4 \\
63.3 \pm 12.6 \\
\end{array}$ & 0.00 & $\begin{array}{l}58.2 \pm 8.9 \\
77.6 \pm 9.9 \\
\end{array}$ & 0.00 & $\begin{array}{c}55.6 \pm 8.3 \\
68.5 \pm 11.3\end{array}$ & 0.00 \\
\hline \multicolumn{7}{|c|}{12 months } \\
\hline $\begin{array}{l}6 \text { weeks } \\
6 \text { months }\end{array}$ & $\begin{array}{c}60.4 \pm 9.7 \\
71.1 \pm 12.7\end{array}$ & 0.00 & $\begin{array}{c}64 \pm 9.1 \\
88.3 \pm 11.3\end{array}$ & 0.00 & $\begin{array}{c}61.80 \pm 9 \\
78.4 \pm 11.7\end{array}$ & 0.00 \\
\hline
\end{tabular}

\section{Neurodevelopmental Outcome}

Neurodevelopmental status in the field of motor, cognition and language continue to show significant improvement among the 6 months group which has started from 6 months of follow up compared to 6 weeks group. This difference is statistically highly significant that has shown in Table VII.

\section{J. Side Effects of Drug}

Most common side effects observed here clinically is the vomiting on both groups, blood picture showed neutropenia among 12 patients, but nobody discontinued drugs due to adverse effects evidenced in Table VIII.

Table VIII: SIDE EFFECTS OF DRUGS AMONG THE STUDIED POPULATION [MEAN \pm SD/ N (\%) AS APPLICABLE]

\begin{tabular}{cccc}
\multicolumn{4}{c}{ POPULATION [MEAN \pm SD/ N (\%) AS APPLICABLE] } \\
\hline \hline \multirow{2}{*}{ Side effects of drugs } & $\begin{array}{c}\text { 6 weeks }(\mathrm{n}=61) \\
\text { Frequency (\%) }\end{array}$ & $\begin{array}{c}\text { 6 months }(\mathrm{n}=62) \\
\text { Frequency (\%) }\end{array}$ & $\begin{array}{c}\mathrm{P} \\
\text { value }\end{array}$ \\
\hline \hline No side effects & $48(78.7)$ & $48(77.4)$ & \\
Vomiting & $6(9.8)$ & $3(4.8)$ & \\
Tremor & $1(1.6)$ & $2(3.2)$ & \\
Drowsiness & $1(1.6)$ & $1(1.6)$ & 0.75 \\
Incoordination & $00(0.0)$ & $1(1.6)$ & \\
Neutropenia & $5(8.2)$ & $7(11.3)$ & \\
\hline \hline
\end{tabular}

\section{DISCUSSION}

Because of some potential side effects of injectable ganciclovir, oral valganciclovir has been introduced in the treatment of congenital CMV infection andit has been proved to be effective with less adverse effects [26]-[31]. Different treatment guidelines now consider valganciclovir as an alternative treatment option for the congenital CMV infection. Six weeks' duration of treatment with valganciclovir is now the accepted treatment regimen but some authors have found longer duration of treatment to maintain the audiologic and neurodevelopmental improvement. Still there is paucity of clinical trials regarding the therapeutic approach of congenital CMV infection. Our study came out with the promising finding of effectiveness of valganciclovir as opposed to ganciclovir in congenital CMV infection in children.

Most of the patients of both groups are from rural and poor socioeconomic background, and both groups showed male predominance, where CMV seropositivity is associated with low socioeconomic status, ethnic minorities and low resource settings [32], [33].

Perinatal asphyxia was a common perinatal complication in both groups associated with the high-risk mother without screening through antenatal checkup. Congenital CMV infection usually impaired the fetal growth as risk of intrauterine transmission after primary infection during early gestation, approaches $40 \%$ [28] which also increases the risk of abortion and fetal demise. Here we found 35\% of our newborn had low birth weight due to IUGR and prematurity. Reference [34] have similar observation on their study

The clinical spectrum of congenital CMV varies widely among the symptomatic group. Common findings are petechiae, jaundice, hepatomegaly, splenomegaly, microcephaly ocular, hearing manifestations, developmental delays, and other neurological signs. Epilepsy is one of the important neurological presentations in both groups found beyond neonatal period. Most common type of seizure was focal and infantile spasm, matched with the finding of [35]. Dystonia was the most common movement disorder experienced by $23.6 \%$ of cases. Gallach ADJ et al. has the same observations, where they explored $46.2 \%$ having sensorineural deafness and $5.6 \%$ with chorioretinitis [36], [37]. In our study visual abnormalities include central visual impairment, chorioretinitis, papilledema and nystagmus, corroborated with the studies where optic atrophy, chorioretinitis and squint were the common ocular findings [38]. While different studies find bilateral sensorineural hearing loss from 3\%-36 \% [39], our study finds $37.4 \%$ mild impairment and $39.8 \%$ moderate impairment. Psychomotor retardation has been common, as no patients came with normal psychomotor development. This is regarded as the most common neurological sequelae from different studies [31], [36], [39].

Among the neuroimage findings, cortical atrophy has been highest ( $86 \%$ ), followed by intracranial calcifications in various location including periventricular area (55.3\%). Van der Knapp et al. have found intracranial calcification among $34-70 \%$ of patients with congenital CMV infection [40], [41]. Looking at congenital malformations of brain, our study excavates $10.6 \%$ corpus callosal agenesis, $5.7 \%$ lissencephaly, and one case of schizencephaly in the 6 months treatment group which is a rare form of migrational defects. These findings are similar to other study findings too [42]-[45].

Our primary outcome was the clearance of virus from urine, for 6 weeks treatment which was observed among 72 $\%$ of patients, $21(33 \%)$ patients from 6 months group and $14(22 \%)$ patients of 6 weeks group showed non clearance of virus, but at the 12 weeks period only 1 patients of 6 months group have shown presence of virus in urine 
whereas 5 patients of 6 weeks have positive test for virus in urine. At the end of 6 months $100 \%$ clearance of virus observed in 6 months group but 3 patients of 6 weeks group still shown existence of CMV DNA in urine though the difference is not statistically significant. Lombardi et al detected CMV DNA $33 \%$ and $50 \%$ from serum and urine and Ohyama et al. detected $12 \%$ and $23 \%$ from blood and urine respectively at the end of 6 weeks treatment of valganciclovir [46],[47]. Nonetheless, most of the infants have shown great reduction of viral load compared to baseline levels.

Our secondary outcome of long term valganciclovir was improvement of hearing, which was evidenced by different clinical trials. Goderis et al. found $32.8 \%$ of newborn with congenital CMV infection exhibited different grade of hearing impairment at birth, similarly Biavsky et al. reported $36.2 \%$ of the children with symptomatic congenital CMV infection experienced hearing impairment from a single center study, whereas Ohyama et al. demonstrated $81 \%$ of their cohort having variable degree of hearing deficits, in our cohort baseline findings of hearing assessment have shown $77 \%$ have mild to severe degree of hearing impairment [47]-[49]. In this study we found a great improvement of hearing from the baseline at 6 months follow up in both groups, but 6 months treatment group exhibit more improvement compared to 6 weeks group $(\mathrm{p}=0.021)$, however it showed greater improvement at 12 months follow up which differed significantly between the two groups, 6 months therapy continue to improve hearing outcome compared to 6 weeks therapy $(p=0.001)$, it indicates that 6 months regimen of valganciclovir improves hearing outcome in long term with respect to short term outcomes over that provided by 6 weeks of treatment. These findings also support the findings of the study done by [39],[47] and our study suggest that CMV infection related moderate to severe hearing dysfunction potentially reversible with antiviral therapy.

A variety of ocular manifestations demonstrated in congenital CMV infection, we found CVI, Chorioretinitis, nystagmus and papilledema among the study population, similar studies conducted by [31],[50],[51] have observed the same changes According to treatment guideline of congenital CMV infection patients with chorioretinitis should have been treated with 6 months oral valganciclovir [52], the reason they were included in 6 months regimen groups and here we found that $89 \%$ (total 8 out of 9 ) patient improved chorioretinitis at the end of 12 months follow up. Other ocular abnormalities like central visual impairment, nystagmus, papilledema all improved at 6 months follow up in both the treatment group, but this improvement maintained better at 12 months follow up among the 6 months treatment group $(\mathrm{p}=0.01)$.

Neurodevelopmental disability in the field of motor, cognitive and language domain is one of the consistent features noticed around $83 \%-87 \%$ of studied population with initial severe impairment assessed by BSID-III. We followed up our groups 3 monthly for 12 months from initial assessment. Improvement of neurodevelopmental outcome is another important secondary outcome where we observed that at the 3 months of follow up period we observed few improvements in both groups, significant improvement started from 6 months follow up period among the 6 months treatment group and maintained very well at 9 month and 12 month follow up period, and the difference was highly significant in all domain $(p=0.00)$. Similar observation from Kimberlin et al where he found improvement of composite score in all components of Bayley-III among the 6-month treatment group though the difference was not significant [39], [47]. Different study has been conducted to see the psychomotor improvement with antiviral therapy like the study of Amir et al. where he treated CMV with intravenous ganciclovir followed by oral valganciclovir up to 12 months of age and found psychomotor retardation $18 \%$ rate which was considerably lower than the $55 \%$ recorded previously [53]. Oliver et al. found treatment with ganciclovir improved developmental delay at both 6 and 12 months in infants who received treatment compared to infant who did not receive treatment [54]. Still there is negligible number of studies to compare the psychomotor improvement on long term use of oral valganciclovir. Here we supported the need of long-term use of oral valganciclovir as we found progressive improvement of motor, cognitive and language domain.

Regarding safety concern oral valganciclovir was well tolerated by both groups of patients, the primary toxicity associated with ganciclovir therapy is hematological abnormalities mostly neutropenia, hypersensitivity, renal, hepatic toxicity, dyselctrolytemia. Valganciclovir is the oral prodrug of ganciclovir have less toxicity compared to ganciclovir, it's also proved in our study where long-term use of valganciclovir has been well tolerated by the patients. We found $7(11.3 \%)$ patients of 6 months group have moderate neutropenia compared to $5(8.2 \%)$ in 6 weeks group. Our second most common side effects were vomiting that was present 9 patients at the initial period of therapy later the symptoms wanes. We found 3 patients with drowsiness, 2 patients with tremor, and 1 patient with incoordination as a manifestations of drug toxicity but the symptoms were managed accordingly, and no patients discontinued the drugs due to the side effects of drug. Kimberli et al was also found drug induced neutropenia as the primary concern during the first 6 weeks of treatment and the risk appears to be reduced when treatment is solely with oral valganciclovir [25], [39].

All the information obtained from this randomized controlled trial signifies that infant with symptomatic congenital CMV infection 6 months treatment with oral valganciclovir have more favorable effects on long term audiologic, neurodevelopmental outcome as well as on virus clearance. Long term use of this drug did not add any detrimental effects on health as well.

\section{CONCLUSION}

Long term use of oral valganciclovir is proved to be effective and safe for the treatment of symptomatic congenital CMV infection in this study. As congenital CMV infection is associated with high community burden especially in the developing country and there is lack of proper preventive strategies, so an effective and well tolerated treatment protocol should be established to prevent long term sequelae. We recommend installing a treatment protocol with 
oral valganciclovir after conducting nationwide research on this topic.

\section{REFERENCES}

[1] Kenneson A, Cannon MJ. Review and metaanalysis of the epidemiology of congenital cytomegalivirus (CMV) infection. Review Med Virol. 2007; 17: 253-76.

[2] Bhattacharya D, Panigrahi I, Chowdhury C. Clinical profile of sypmtomatic congenital cytomegalovirus infection: Cases from a tertiary hospital in north India. Tropical Doctor. 2020; 0(0): 1-3.

[3] Orney A, Citrin OD. Fetal effects of primary and secondary cytomegalovirus infection in pregnancy. Reproductive Toxicology. 2006; $21: 399-409$.

[4] Gargouri J, Ellueuch H, Rekik H, Hammani A. Prevalence of antiCMV antibodies in blood donors in the Sfax region. Tunis Med. 2000; 78: 512-7.

[5] Pultoo A, Meetoo G, Pydiah MN, Khittoo G. Seroprevalence of cytomegalovirus infection in Mauritian volunteer blood donors. Indian J Med Sci. 2001; 55: 73-8.

[6] Schopfer K, Lauber E, Krech U. Congenital cytomegalovirus infection in newborn infants of mothers infected before pregnancy. Arch Dis Child. 1978; 53: 536-9.

[7] Stagno S, Reynolds DW, Huang ES. Congenital cytomegalovirus infection: occurrence in an immune population. N Engl J Med. 1977; 296: $1254-8$

[8] Muller WJ. Treatment of perinatal viral infections to improve neurologic outcomes. Pediatr Res. 2017; 81: 162-9.

[9] Leung AKC, Sauve RS, Davies HD. Congenital Cytomegalovirus. J Natl Med Assoc. 2003; 95(3): 213-8.

[10] Naing ZW, Scott GM, Shand A, Hamilton ST, Zuylen WJ, Basha J, et al. Congenital cytomegalovirus infection in pregnancy: a review of prevalence, clinical features, diagnosis, and prevention. Aust $N Z L$ Obstet Gynaecol. 2016; 56: 9-18.

[11] Stagno S. Breastfeeding and transmission of cytomegalovirus infections. Ital J Pediatr. 2002; 28: 275-80.

[12] Nassetta L, Kimberlin D, Whitley R. Treatment of congenital cytomegalovirus infection: implications for future therapeutic strategies. Journal of Antimicrobial Chemotherapy 2009; 63: 862-7.

[13] James SH, Kimberlin DW. Advances in the prevention and treatment of congenital cytomegalovirus infection. Curr Opin Pediatr. 2016; 28 $81-85$.

[14] Bialas KM, Geeta K, Swamy GK, Permar SR. Perinatal cytomegalovirus and varicella zoster virus infections: Epidemiology, Prevention and Treatment. Clin Perinatal. 2015; 42: 61-75.

[15] Dollard SC, Grosse SD, Ross DS. New estimates of the prevalence of neurological and sensory sequelae and mortality associated with congenital cytomegalovirus infection. Rev Med Virol. 2007; 17: $255-$ 63.

[16] Marsico C, Kimberlin DW. Congenital cytomegalovirus infection: advances and challenges in diagnosis, prevention, and treatment. Italian Journal of Periatrics. 2017; 43: 38.

[17] Rausseau T, Douvier S, Reynaud I, Laurent N, Bour JB, Durand C, et al. Severe fatal cytomegalic inclusion disease after documented mental reactivation of cytomegalovirus infection during pregnancy. Prenat Diag. 2000; 20: 333-6.

[18] Gaytant MA, Rours GI, Steegers EA, Galama JM, Semmekrot BA. Congenital cytomegalovirus infection after recurrent infection case reports and review of the literature. Eur J Pediatr. 2003; 162: 248-53.

[19] Bounsenso D, Serranti D, Gargiullo L, Cecarelli M, Ranno O, Vlentini P. Congenital cytomegalovirus infection: current strategies and future perspectives. Eur Rev Med Pharmacol Sci. 2012; 16(7): 919-35.

[20] Foulon I, Naessens A, Foulon W, Casteels A, Gordts F. A 10-year prospective study of sensorineural hearing loss in children with congenital cytomegalovirus infection. J Pediatr. 2008; 153: 84-8.

[21] Fowler KB, McCollister FP, Dahle AJ, Boppana S, Britt WJ, Pass RF. Progressive and fluctuating sensorineural hearing loss in children with asymptomatic congenital cytomegalovirus infection. J Pediatr 1997; 130: 624-30.

[22] Mocarski ES, Shenk T, Pass RF. Cytomegalovirus. Virology 5th edn. Philadelphia: Lippincott Williams and Wilkins, 2007: 2701-72.

[23] Kimberlin DW, Acosta EP, Sanchez PJ, Sood S, Agrawal V, Homans $\mathrm{J}$, et al. Pharmacokinetic and pharmacodynamic assessment of oral valganciclovir in the treatment of symptomatic congenital cytomegalovirus disease. J Infect Dis. 2008; 197: 836-45.

[24] Acosta EP, Brundage RC, King JR, Sanchez PJ, Sood S, Agrawal V, et al. Ganciclovir population pharmacokinetics in neonates following intravenous administration of ganciclovir and oral administration of a liquid valganciclovir formulation. Clin Pharmacol Ther. 2007; 81: 867-72.

[25] Kimberlin DW, Lin CY, Sanchez PJ, Kiell JM, Soong SJ, Whitley RJ, et al. Effect of ganciclovir therapy on hearing in symptomatic congenital cytomegalovirus disease involving the central nervous system: a randomized controlled trial. J Pediatr. 2003; 143: 16-25.

[26] Meine Jansen CF, Toet MC, Rademaker CM, Ververs TF, Gerards LJ, Van Loon AM. Treatment of symptomatic congenital cytomegalovirus infection with valganciclovir. J Perinat Med. 2005; 33: 364-6.

[27] Mullar A, Eis-Hubinger AM, Brandhorst G, Heep A, Bartmann P, Franz AR. Oral valganciclovir for symptomatic congenital cytomegalovirus infection in an extremely low birth weight infant. $J$ Perinatol. 2008; 28: 74-76.

[28] Shoji K, Ito N, Ito Y, Inoue N, Adachi S, Fujimaru T, et al. Is a 6 week course of gamciclovir therapy effective for chorioretinitis in infants with congenital cytomegalovirus infection? J Pediatr. 2010; 157: 3313.

[29] Kashiwagi Y, Kawashima H, Nakajima J, Ishida Y, Nishimata S, Miyajima T, et al. Efficacy of prolonged valganciclovir therapy for congenital cytomegalovirus infection. J Infect Chemother. 2011; 17: $538-40$

[30] Tanaka-Kitajima N, Sugaya N, Futatani T, Kanegane H, Suzuki C, Oshiro M, et al. Ganciclovir therapy for congenital cytomegalovirus infection in six infants. Pediatr Infect Dis J. 2005; 24: 782-5.

[31] Fatema K, Rahman MM, Akhtar S, Shefa J. Efficacy of Valganciclovir versus Ganciclovir in treatment of symptomatic cytomegalovirus infection in infants: An open level randomized controlled trial. Journal of International Child Neurology Association. 2019.

[32] Munro SC, Hall B, Whybin LR, Leader L, Robertson P, Maine GT, et al. Diagnosis of and screening for cytomegalovirus infection in pregnant woman. J Clin Microbiol. 2005; 43: 4713-18.

[33] Seale H, Macintyre CR, Gidding HF, Backhouse JL, Dwyer DE, Gilbert I. National serosurvey of cytomegalovirus in Australia. Clin Vaccine Immunol. 2006; 13: 1181-84.

[34] Yashinago-Itano C, Sedey AL, Coulter DK, Mehl AL. Language of early and later identified children with hearing loss. Pediatrics. 1998; 102: 1161-71.

[35] Yasuhiro S, Yasuhisa T, Yukiko M, Keiko Y, Masanori N. Epilepsy in patients with congenital cytomegalovirus infection. Brain and Development. 2008; 30: 420-24

[36] Gallach ADJ, Albert MA, Harnandez AVM, Gonzalez NB, Badia MC Vila MT. Neurological sequelae in patients with congenital cytomegalovirus. An Pediatr(Brac). 2020; 93: 111-17.

[37] Plosa EJ, Esbenshade JC, Fuller MP, Weitkamp JH. Cytomegalovirus infection. Pediatrics in Review. 2012; 33: 156-63.

[38] Sakiko F, Satoshi I, Shin-ya N, Hideaki M, Shin-ichi U. Clinical profile of hearing loss in children with congenital cytomegalovirus (CMV) infection: CMV DNA diagnosis using preserved umbilical cord. Acta Oto-Laryngologica. 2011; 131: 976-82.

[39] Kimberlin WD, Penelope M, Jester BSN, Sanchez PJ, Ahmed A, Boger RA, et al. Valganciclovir for symptomatic congenital cytomegalovirus disease. $N$ Engl J Med. 2015; 372: 933-43.

[40] Van der Knapp MS, Vermeulen G, Barkhof F, Hart AAM, Loeber JG, Weel JFL. Pattern of white matter at MR imaging: use of polymerase chain reaction testing of Guthrie cards to link pattern with congenital cytomegalovirus infection. Radiology. 2004; 230: 529-36.

[41] Moore KR, Jones BV, Vezina G, Koch BL, Raybaud C, Grant PE, et al. Diagnostic imaging: pediatric neuroradiology. Diagnostic Imaging Pediatric Neuroradiology. 2017: 82-85.

[42] Hayward JC, Titelbaum DS, Clancy RR, Zimmerman RA. Lissencephaly-pachygyria associated with congenital cytomegalovirus infection. J Child Neurol. 1991; 6: 109-14.

[43] Arpino C, Gattinara GC, Rosso M, Pelliccia A, Fariello G, Curatolo P. Cortical maldevelopment in congenital cytomegalovirus infection transmitted by a woman with preexisting immuniity. $J$ Neurovirol. 2008; 14: 173-6.

[44] Zucca C, Binda S, Borgatti R, Triulzi F, Radice L, Butte C, et al. Retrospective diagnosis of congenital cytomegalovirus infection and cortical maldevelopment. Neurology. 2003; 61: 710-12.

[45] Iannetti P, Nigro G, Spalice A, Faiella A, Boncinelli E. Cytomegalovirus infection and scizencephaly. Annals of Neurology. 1998; 43: 123-7.

[46] Lombardi G, Garofoli F, Villani I, Tizzoni M, Angelini M, Cusato M. Oral valganciclovir treatment in newborns with symptomatic congenital cytomegalovirus infection. Eur J Clin Microbiol Infect Dis. 2009; 28: 1465-70

[47] Ohyama S, Morioka I, Fukushima S, Yamana K, Nishida K, Iwatani S, et al. Efficacy of valganciclovir treatment depends on the severity on the hearing dysfunction in symptomatic infants with congenital 
cytomegalovirus infection. International Journal of Molecular Sciences. 2019; 20: 1388

[48] Goderis J, De Leenheer E, Smets K, Van Hoecke H, Keymeulen A, Dhooge I. Hearing loss and congenital CMV infection: a systemic review. Pediatrics. 2014; 134: 972-82.

[49] Bilavsky E, Shahar-Nissan K, Pardo J, Attias J, Amir J. Hearing outcome of infants with congenital cytomegalovirus and hearing impairment. Arch Dis Child. 2016; 101: 433-8.

[50] Boppana SB, Ross SA, Fowler KB. Congenital cytomegalovirus infection: clinical outcome. Clin Infect Dis. 2013; 57: 178-81.

[51] Plosa EJ, Esbenshade JC, Fuller MP, Weitkamp JH. Cytomegalovirus infection. Pediatrics in Review. 2012; 33: 156-63.

[52] Whitly RJ, Cloud G, Gruber W, Storch GA, Demmler GJ, Jacobs RF, et al. Ganciclovir treatment of symptomatic congenital cytomegalovirus infection: results of a phase II study. National institute of allergy and infectious diseases collaborative antiviral study group. $J$ Infect Dis. 1997; 175: 1080-86.

[53] Amir J, Wolf DG, Levy I. Treatment of symptomatic congenital cytomegalovirus infection with intravenous ganciclovir followed by long term oral valganciclovir. European J Pediatr. 2010; 169: 106167.

[54] Oliver S, Cloud G, Sanchez P, Demmler G, Dankner W, Shelton M, et al. Neurodevelopmental outcomes following ganciclovir therapy in symptomatic congenital cytomegalovirus infections involving central nervous system. J Clin Virol. 2009; 46: 22-26. 